\title{
Does the longevity of one or both parents influence the health status of their offspring?
}

\author{
P. Gueresi ${ }^{\text {a,* }}$, R. Miglio ${ }^{\text {a }}$, D. Monti ${ }^{\text {b }}$, D. Mari ${ }^{\text {c,d }}$, P. Sansoni ${ }^{\text {e }}$, C. Caruso ${ }^{\text {f }}$, E. Bonafede ${ }^{\text {a }}$, L. Bucci ${ }^{\text {g, E. Eevenini }}{ }^{\text {g, }}$, \\ R. Ostan ${ }^{\text {g }}$, M.G. Palmas ${ }^{\text {g, E. Pini }}{ }^{g}$, M. Scurti ${ }^{g}$, C. Franceschi ${ }^{\text {g,h }}$ \\ a Department of Statistical Sciences, University of Bologna, Via Belle Arti, 41, 40126 Bologna, Italy \\ ${ }^{\mathrm{b}}$ Department of Clinical and Experimental Biomedical Sciences, University of Florence, Viale Morgagni, 50, 50134 Florence, Italy \\ c Department of Medical Sciences, University of Milan, Via F. Sforza, 35, 20122 Milan, Italy \\ ' Geriatric Unit IRCCS Ca' Granda Foundation Maggiore Policlinico Hospital, 20122 Milan, Italy \\ e Department of Internal Medicine and Biomedical Sciences, University of Parma, Via Gramsci, 14, 43126 Parma, Italy \\ ${ }^{\mathrm{f}}$ Immunosenescence Unit, Department of Pathobiology and Biomedical Methodologies, University of Palermo, Corso Tukory, 211, 90100 Palermo, Italy \\ g C.I.G. Interdepartmental Centre “L. Galvani”, University of Bologna, Via San Giacomo, 12, 40126 Bologna, Italy \\ ${ }^{\mathrm{h}}$ Department of Experimental Diagnostic and Specialty Medicine, University of Bologna, Via San Giacomo, 12, 40126 Bologna, Italy
}

\section{A R T I C L E I N F O}

\section{Article history:}

Received 19 July 2012

Received in revised form 5 January 2013

Accepted 3 February 2013

Available online 10 February 2013

Section Editor: Diana Van Heemst

\section{Keywords:}

Healthy aging

Familial longevity

Centenarians' offspring

Health status

Functional status

\begin{abstract}
A B S T R A C T
According to the findings of some recent studies, the centenarians' offspring appear to represent a promising model for research on longevity and healthy aging. This study compares the health status and the functional status of three groups of subjects: 1 . individuals with two long-lived parents (one of whom centenarian), 2. individuals with only one long-lived (centenarian) parent, and 3. individuals with no long-lived parents. The goal is to verify whether the centenarians' offspring display any advantage over the offspring of both non-long-lived parents and to evaluate whether the longevity of the non-centenarian parent provides a further advantage. A total of 374 subjects (mean age approximately 70 years) was examined. A threshold for longevity was established for non-centenarian parents through demographic data available for Italy (males surviving to at least 81 years of age and females to 87 years). The participants were assessed for their health and functional status by means of a standardized questionnaire and tests of physical performance. Data were analyzed using multivariate regression models adjusted for socio-demographic characteristics and risk factors for age-related pathologies.

The results of the study show that centenarians' offspring have a better functional status, a reduced risk for several age-related pathologies and reduced drug consumption than the offspring of non-long-lived parents. In addition, the health status of centenarians' offspring does not appear to be influenced by the longevity of the second parent. It therefore seems possible to conclude that at ages around 70 years the genetic contribution to health status deriving from having one centenarian parent is not substantially improved if the other parent is also long-lived.
\end{abstract}

(c) 2013 Elsevier Inc. All rights reserved.

\section{Introduction}

Over the past twenty years, centenarians have represented a valuable resource for the study of phenotypic characteristics of extreme aging and the genetic and environmental factors of longevity. The aging process is characterized by a complex remodeling of organs

\footnotetext{
* Corresponding author. Tel.: + 39051 2098242; fax: + 39051232153.

E-mail addresses: paola.gueresi@unibo.it (P. Gueresi), rossella.miglio@unibo.it (R. Miglio), daniela.monti@unifi.it (D. Monti), daniela.mari@unimi.it (D. Mari), paolo.sansoni@unipr.it (P. Sansoni),marcoc@unipa.it (C. Caruso), laura.bucci2@unibo.it (L. Bucci), elisa.cevenini3@unibo.it (E. Cevenini), rita.ostan3@unibo.it (R. Ostan), mariagiustina.palmas@unibo.it (M.G. Palmas), elisa.pini5@unibo.it (E. Pini), maria.scurti@unibo.it (M. Scurti), claudio.franceschi@unibo.it (C. Franceschi).
}

and tissues in order to cope with the lifelong exposure to biological, physical and chemical stressors, so that longevity can be attained by efficient mechanisms of adaptation and remodeling capacity. Indeed, the centenarians display a peculiar, complex and heterogeneous phenotype, which might be the result of a better capacity of their body to adapt and remodel in response to biological and non-biological stimuli (Franceschi et al., 2000, 2007b).

Moreover, centenarians seem to reach their extreme age thanks to a slower aging process and have a lower prevalence of cancer (Salvioli et al., 2009), cardiovascular diseases (CVD) (Olivieri et al., 2008), insulin-resistance and diabetes (Paolisso et al., 1996) and delay of about 1-2 decades the onset of others pathologies such as dementia and osteoporothic fractures (Evert et al., 2003; Passeri et al., 2003).

Furthermore, the great majority of them has optimal anthropometric (body mass index, BMI), metabolic (cholesterol, LDL-C, HDL-C, 
triglycerides) and cardiovascular (systolic and diastolic pressure) parameters for their age (Spazzafumo et al., 2011).

However, research on centenarians has to face several methodological difficulties. The first is the rarity of centenarians (e.g. in Italy about 27 for every 100,000 residents at 1st January 2011 according to the National Institute of Statistics ISTAT), which makes recruitment rather difficult. Moreover, it is very hard to perform population-based cross-sectional studies on centenarians (Gueresi et al., 2003) due to the very high mortality rate at extremely advanced ages. Finally, there is no appropriate control group for centenarians.

No less important are the ethical and practical questions that have to be dealt with when approaching subjects who are very frail and sometimes easily tired.

Recently, the attention of some researchers has focused on the offspring of centenarians as a model for longevity and healthy aging. Longevity is known to have a strong familial (and genetic) component (De Benedictis and Franceschi, 2006; Franceschi et al., 2007a) and recent studies suggest that the offspring of centenarians have a significant survival advantage, a higher probability to become longlived and a lower risk of age-related diseases, such as cardio- and cerebro-vascular diseases, compared to control subjects (Adams et al., 2008; Atzmon et al., 2004; Perls et al., 2002; Terry et al., 2003, $2004 a, b)$. At the same time, the study of the offspring of centenarians reduces or resolves the disadvantages related to research on centenarians themselves. Being younger, their offspring are less rare and easier to recruit, less frail and less likely to die within short time. Moreover, they can be compared with age-matched control groups.

The research project "Does the longevity of parents influence the health status of their offspring?" supported by the Ministry of Education, University and Research (MIUR), aims to evaluate the role of longevity in one or both parents on the quality of their offspring's aging and to identify biological parameters and genetic polymorphisms related to healthy aging. This paper will present the study design and will compare the offspring of centenarians and the offspring of subjects who were not long-lived as regards several phenotypic characteristics. The goal is to verify whether the children of centenarians display any advantage when compared to the offspring of non-long-lived subjects, evaluating at the same time whether having two long-lived parents (one of whom centenarian) represents a further advantage over having only one long-lived (centenarian) parent. It is worth noting that an accurate demographic analysis of the age of the non-centenarian parent was performed, giving a further value to this study since it was never taken into consideration in previous research on centenarians' offspring.

The studied variables concern both objective and perceived state of health, with special attention on the physical-functional state as well as on the pathologies and risk factors related to the main causes of death among the elderly.

\section{Materials and methods}

\subsection{Defining longevity criteria for group identification}

The aims of the study entailed the need to compare three groups of subjects: 1 . offspring of two long-lived parents, one of whom centenarian (LL); 2. offspring of one centenarian parent and one nonlong-lived parent $(\mathrm{NL})$; and 3 . offspring of both non-long-lived parents (NN).

In order to identify the above mentioned groups, rigorous demographic criteria were applied to establish the threshold age over which subjects were classified as long-lived. These criteria take into account the distribution of deaths, according to the estimates of the Human Mortality Database for the five-year birth cohorts to which the parents of the subjects recruited belong. Since it was decided to recruit, in 2007 and 2008, offspring of at least one living centenarian parent, born therefore presumably between 1900 and 1908, the birth cohorts of the centenarians' spouses were estimated to fall between 1890-94 and 1910-14 cohorts. The parents of NN subjects belong to the same cohorts.

According to estimates from the Human Mortality Database, distribution of Italian male deaths in the cohorts of interest (excluding deaths occurred before the age of 15 years) has the form of a negatively asymmetrical curve (Fig. 1), although distribution during the 1890-94 and 1895-99 cohorts is sharply altered by the effects on mortality of the First World War. The effects of aging on mortality start to become apparent from about the age of fifty. In the central cohort 1900-1904 the 85th-percentile of the distribution of all deaths falls between the 81st and the 82nd birthday, therefore about $15 \%$ of all male deaths in this birth cohort occurred at or over the age of 81 years. It was decided to consider as non-long-lived males those deceased before reaching the age of 81 years. This longevity threshold can be considered essentially valid also for the previous and subsequent five-year birth cohorts despite the different life expectancy of the cohorts. In fact, although the threshold value causes the number of deaths per cohort to be apportioned differently, so that the long-lived may be little more or little less than $15 \%$, it lies in the descending phase of the curve of deaths.

Using the same procedure, females deceased before reaching the age of 87 years were considered to be non-long-lived (Fig. 2).

\subsection{Recruitment and data collection}

A list of eligible subjects for the study was obtained thanks to the help from Registry Offices in five Italian cities (Bologna, Milan, Florence, Parma and Palermo) and surrounding areas. Offspring of parents who died from accidental causes were excluded. A total of 374 subjects were recruited and attributed to the LL, LN and NN groups on the basis of the previously illustrated demographic criteria. Where possible, for each centenarian the oldest child was contacted. Centenarian parents were still alive at the time of the interview. The mean and standard deviation of the age at death of the second parent were $89.1 \pm 4.7$ for the LL group and $66.2 \pm 12.4$ for the $L N$ group. In the NN group, the oldest parent died at a mean age of $64.6 \pm 7.0$, while the youngest died at a mean age of $53.5 \pm 10.9$.

The study protocol was approved by the Ethical Committee of Sant'Orsola-Malpighi University Hospital (Bologna, Italy).

The recruited subjects were examined in their own homes by a team composed by a physician and a biologist specifically trained to gather the data. Besides undergoing an objective exam and giving a blood sample, the participants answered a questionnaire which covered socio-demographic characteristics, lifestyle, pathological and pharmacological anamnesis and evaluation of their perceived

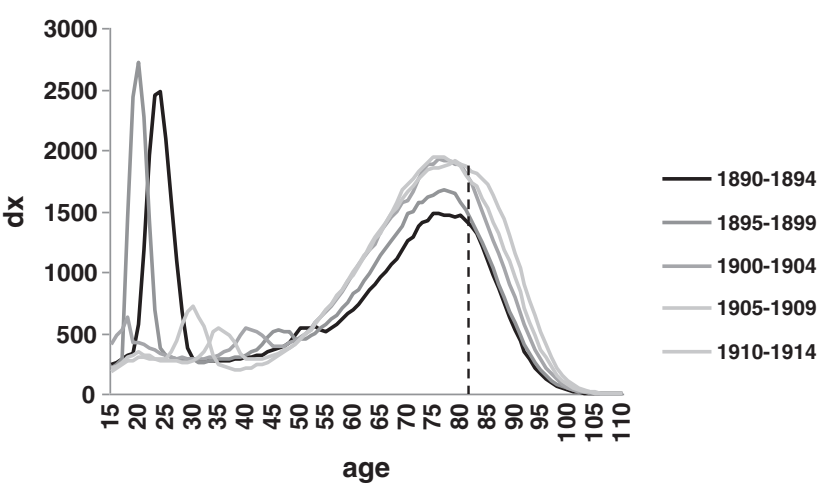

Fig. 1. Distribution of Italian male deaths in five quinquennial birth cohorts according to the estimates of the Human Mortality Database $\left(d_{x}=\right.$ number of deaths occurring between the age $x$ and the age $x+1$ in a cohort of 100,000 births). The vertical dashed line indicates the longevity threshold. 


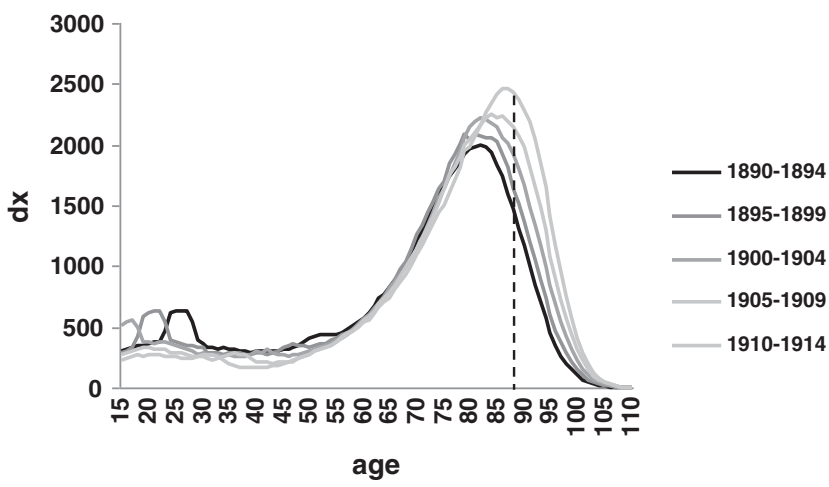

Fig. 2. Distribution of Italian female deaths in five quinquennial birth cohorts according to the estimates of the Human Mortality Database $\left(d_{x}=\right.$ number of deaths occurring between the age $x$ and the age $x+1$ in a cohort of 100,000 births). The vertical dashed line indicates the longevity threshold.

state of health. They also underwent various tests to assess physical and cognitive performances.

Regarding the evaluation of general state of health, typical age-related diseases and the pathological conditions representing the main causes of death among the elderly were considered. Pathologies and chronic conditions are documented by medical reports or by specific ongoing therapies.

It should be pointed out that the data reported here have not been gathered in order to estimate the prevalence of pathological conditions. This is particularly true in the case of cancer, since subjects with severe health problems due to overt cancer have been excluded from the study.

Chronic therapies (i.e. daily drug consumption under medical prescription, such as cardiovascular, antihypertensive, lipid-lowering and anti-diabetic drugs) and the number of drugs taken daily were included in the analysis as general health indicators.

Finally, perceived health state of subjects was considered. The approach was devised to include both qualitative (state of health selfevaluated as "very good", "good", "normal", "poor" or "very poor") and quantitative assessments (self-rated state of health with a score ranging from 0 to 100). Perceived health has been reported dichotomously because very few subjects claimed that their health was "poor" or "very poor".

The functional status of the participants was described by an item concerning their ability to walk $500 \mathrm{~m}$ without help or device. Moreover, hand grip strength was measured with a Smedley's dynamometer (Scandidact, Kvistgaard, Denmark) and the best of two performances with the dominant hand was considered for the analysis. The chairstand test was also performed, i.e. the time taken to sit down-stand up from a chair five consecutive times.

Socio-demographic characteristics like gender, age, marital status, education (years), as well as several recognized risk factors for age-related pathologies, such as smoking (present or past smoking for at least 10 years or at least 10 cigarettes a day), wine consumption (number of glasses drunk daily during lifetime), BMI (normal and underweight vs. overweight and obese) and physical activity (subjects who claimed to practice regular physical exercise vs. subjects who did not) were considered as possible confounders.

\subsection{Data and statistical analysis}

Socio-demographic, functional and clinical characteristics in the three groups of subjects with two, one or no long-lived parents have been firstly examined by means of univariate statistics (ANOVA, Kruskal-Wallis, Chi-square test or Fisher's exact test, as appropriate). For a more thorough investigation of the relations among functional status or health status and the three groups, several multiple regression models have been developed. Regression models were adjusted for the effects of gender, age, marital status, education, BMI, physical activity, smoking and wine consumption.

The continuous dependent variables were studied with multivariate linear regression models and regression coefficients with 95\% confidence interval $(\mathrm{CI})$ were reported. The dichotomous dependent variables were analyzed with logistic regression models and the odds ratio (OR) with $95 \%$ confidence interval was used as a measure of association. When the dependent variable represented a count (i.e. the number of drugs assumed), a Poisson regression model was estimated and the incidence rate ratio with $95 \%$ CI was reported.

\section{Results}

Table 1 shows the general characteristics of subjects with two long-lived parents, one of which centenarian (LL), those with only one long-lived (centenarian) parent (LN), and subjects without long-lived parents (NN). The number of cases is greater in LN group, enabling the continuation of the study to include a possible subdivision of this group according to the gender of the long-lived/nonlong-lived parents. The gender composition of the groups is balanced somewhat in favor of the females in LN group, where there is also a significantly lower proportion of married subjects. Among the socio-demographic variables there are also significant differences in education level, higher in LL group.

Table 1

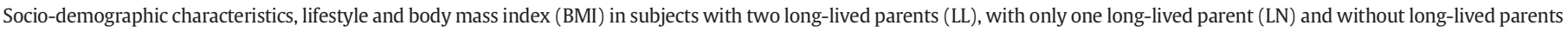
(NN). p-values refer to univariate statistics (ANOVA, Kruskal-Wallis, Chi-square test or Fisher's exact test, as appropriate).

\begin{tabular}{|c|c|c|c|c|}
\hline & & $\operatorname{LL}(\mathrm{n}=83)$ & LN $(n=183)$ & NN $(n=107)$ \\
\hline \multirow[t]{2}{*}{ Gender $^{\mathrm{a}}$} & Males, \%(n) & $49.4(41)$ & $36.6(67)$ & $51.4(55)$ \\
\hline & Females, \%(n) & $50.6(42)$ & $63.4(116)$ & $48.6(52)$ \\
\hline \multirow[t]{2}{*}{ Marital status $^{\mathrm{b}}$} & Married, \%(n) & $69.9(58)$ & $54.6(100)$ & $76.6(82)$ \\
\hline & Unmarried, widowed, divorced, \%(n) & $30.1(25)$ & $45.4(83)$ & $23.4(25)$ \\
\hline \multirow{2}{*}{ Smoking habits } & Smokers, \%(n) & $43.4(36)$ & $45.4(83)$ & $43.0(46)$ \\
\hline & Non-smokers, \%(n) & $56.6(47)$ & $54.6(100)$ & $57.0(61)$ \\
\hline \multirow[t]{3}{*}{ Wine consumption } & Teetotalers, \%(n) & $34.1(28)$ & $47.1(81)$ & $39.4(41)$ \\
\hline & 1-2 glasses/day, \%(n) & $56.1(46)$ & $48.3(83)$ & $53.9(56)$ \\
\hline & 3 or more glasses/day, \%(n) & $9.8(8)$ & $4.6(8)$ & $6.7(7)$ \\
\hline \multirow[t]{2}{*}{ Regular physical exercise } & Yes, \%(n) & $62.2(51)$ & $63.9(117)$ & $69.8(74)$ \\
\hline & No, \%(n) & $37.8(31)$ & $36.1(66)$ & $30.2(32)$ \\
\hline Age & Mean \pm SD (n) & $69.0 \pm 6.2(83)$ & $70.8 \pm 6.6(183)$ & $71.1 \pm 6.0(107)$ \\
\hline Education years ${ }^{\mathrm{a}}$ & Mean \pm SD $(\mathrm{n})$ & $12.1 \pm 5.2(83)$ & $10.8 \pm 4.9(183)$ & $10.1 \pm 4.3(107)$ \\
\hline BMI $\left(\mathrm{kg} / \mathrm{m}^{2}\right)$ males & Mean \pm SD (n) & $26.8 \pm 2.7(41)$ & $27.0 \pm 3.9(65)$ & $27.8 \pm 3.9(55)$ \\
\hline BMI $\left(\mathrm{kg} / \mathrm{m}^{2}\right)$ females ${ }^{\mathrm{a}}$ & Mean \pm SD (n) & $25.7 \pm 4.4(41)$ & $26.5 \pm 5.2(113)$ & $28.5 \pm 4.5(51)$ \\
\hline
\end{tabular}

\footnotetext{
a $\mathrm{p}<0.05$.
}

b $\mathrm{p}<0.01$. 
Table 2

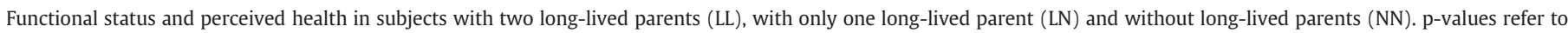
univariate statistics (ANOVA, Kruskal-Wallis, Chi-square test or Fisher's exact test, as appropriate).

\begin{tabular}{|c|c|c|c|c|}
\hline & & $\operatorname{LL}(\mathrm{n}=83)$ & $\mathrm{LN}(\mathrm{n}=183)$ & $\mathrm{NN}(\mathrm{n}=107)$ \\
\hline \multirow[t]{2}{*}{ Ability to walk $500 \mathrm{~m}$ without help } & Yes, \%(n) & $96.3(79)$ & $95.1(174)$ & $89.6(95)$ \\
\hline & No, \%(n) & $3.7(3)$ & $4.9(9)$ & $10.4(11)$ \\
\hline \multirow{2}{*}{ Ability to perform the chair-stand test ${ }^{\mathrm{a}}$} & Yes, \%(n) & $97.1(68)$ & $95.3(161)$ & $84.6(88)$ \\
\hline & No, \%(n) & $2.9(2)$ & $4.7(8)$ & $15.4(16)$ \\
\hline Chair-stand (s) males & Mean $\pm S D(n)$ & $11.1 \pm 3.8(31)$ & $11.0 \pm 2.8(58)$ & $11.7 \pm 4.4(48)$ \\
\hline Chair-stand (s) females & Mean \pm SD (n) & $12.1 \pm 4.9(37)$ & $12.6 \pm 4.9(102)$ & $13.4 \pm 3.3(40)$ \\
\hline Hand grip strength $(\mathrm{kg})$ males & Mean \pm SD (n) & $39.4 \pm 7.5(41)$ & $37.7 \pm 7.0(67)$ & $37.4 \pm 7.4(54)$ \\
\hline Hand grip strength $(\mathrm{kg})$ females ${ }^{\mathrm{a}}$ & Mean \pm SD (n) & $23.8 \pm 6.7(42)$ & $23.8 \pm 5.1(110)$ & $21.2 \pm 5.0(51)$ \\
\hline Self-rated health score $(0-100)$ & Mean \pm SD (n) & $77.0 \pm 13.1(82)$ & $76.3 \pm 16.7(183)$ & $72.7 \pm 16.5(105)$ \\
\hline \multirow[t]{2}{*}{ Perceived health } & Good or very good, \%(n) & $62.2(51)$ & $62.4(113)$ & $50.0(52)$ \\
\hline & Normal, poor or very poor, \%(n) & $37.8(31)$ & $37.6(68)$ & $50.0(52)$ \\
\hline
\end{tabular}

${ }^{\mathrm{a}} \mathrm{p}<0.05$.

Mean age and lifestyle are similar in the three groups. BMI values are higher in NN group, but differences are significant only in females.

A better functional status in the LL and LN groups in comparison with NN group is revealed by significant differences in the ability to perform the chair-stand test and, among females, in the hand grip strength (Table 2). Among those who were able to conclude the chair-stand test, NN group on average shows the worst performance, however the differences are not statistically significant. Moreover, in the group in which neither parent was long-lived, both the percentage of subjects who consider their health status as good or very good and the self-rated health score are lower, even though not significantly (Table 2).

A notable variability in the presence of pathologies can be observed in the three groups with different parental longevity (Table 3). In particular, systematically higher percentages of subjects suffering from pathologies or who exhibit risk factors for age-associated diseases are recorded in the group with no long-lived parents. The differences between the groups are significant in their need for chronic therapy and number of drugs taken daily, as well as for frequency of cancer, hypertension, myocardial infarction and stroke/thrombosis/cerebral hemorrhage. Finally, it can also be noted that for two other pathological conditions, chronic obstructive pulmonary disease (COPD) and chronic renal failure, the differences between the groups are close to statistical significance (respectively 0.062 and 0.061 ).

Table 3

Health status in subjects with two long-lived parents (LL), with only one long-lived parent (LN) and without long-lived parents (NN). p-values refer to univariate statistics (ANOVA, Kruskal-Wallis, Chi-square test or Fisher's exact test, as appropriate).

\begin{tabular}{|c|c|c|c|c|}
\hline & & $\begin{array}{l}\mathrm{LL} \\
(\mathrm{n}=83)\end{array}$ & $\begin{array}{l}\text { LN } \\
(n=183)\end{array}$ & $\begin{array}{l}\text { NN } \\
(n=107)\end{array}$ \\
\hline \multirow{2}{*}{$\begin{array}{l}\text { Stroke or myocardial } \\
\text { infarction }^{\mathrm{b}}\end{array}$} & Yes, \%(n) & $7.3(6)$ & $5.0(9)$ & $17.3(18)$ \\
\hline & No, \%(n) & $92.7(76)$ & $95.0(172)$ & $82.7(86)$ \\
\hline \multirow[t]{2}{*}{ Hypertension $^{\mathrm{b}}$} & Yes, \%(n) & $37.4(31)$ & $41.5(76)$ & $63.6(68)$ \\
\hline & No, \%(n) & $62.6(52)$ & $58.5(107)$ & $36.4(39)$ \\
\hline \multirow[t]{2}{*}{ Hypercholesterolemia } & Yes, \%(n) & $36.1(30)$ & $33.3(61)$ & $42.5(45)$ \\
\hline & No, \%(n) & $63.9(53)$ & $66.7(122)$ & $57.5(61)$ \\
\hline \multirow[t]{2}{*}{ Diabetes } & Yes, \%(n) & $8.4(7)$ & $10.4(19)$ & $11.3(12)$ \\
\hline & No, \%(n) & $91.6(76)$ & $89.6(164)$ & $88.7(94)$ \\
\hline \multirow[t]{2}{*}{ Cancer $^{\mathrm{a}}$} & Yes, \%(n) & $7.2(6)$ & $11.1(20)$ & $19.1(20)$ \\
\hline & No, \%(n) & $92.8(77)$ & $88.9(161)$ & $80.9(85)$ \\
\hline \multirow[t]{2}{*}{ COPD } & Yes, \%(n) & $1.2(1)$ & $4.4(8)$ & $8.5(9)$ \\
\hline & No, \%(n) & $98.8(82)$ & $95.6(175)$ & $91.5(97)$ \\
\hline \multirow[t]{2}{*}{ Chronic renal failure } & Yes, \%(n) & $2.4(2)$ & $0.6(1)$ & $4.7(5)$ \\
\hline & No, \%(n) & $97.6(81)$ & $99,4(182)$ & $95.3(101)$ \\
\hline \multirow[t]{2}{*}{ Chronic therapy $^{\mathrm{b}}$} & Yes, \%(n) & $72.3(60)$ & $80.9(148)$ & $93.4(99)$ \\
\hline & No, \%(n) & $27.7(23)$ & $19.1(35)$ & $6.6(7)$ \\
\hline $\begin{array}{l}\text { Number of drugs } \\
\text { taken daily }\end{array}$ & $\begin{array}{l}\text { Median, IQR } \\
\text { (n) }\end{array}$ & $\begin{array}{l}2.0,1.0-4.0 \\
(72)\end{array}$ & $\begin{array}{l}3.0,1.0-4.0 \\
(167)\end{array}$ & $\begin{array}{l}3.5,2.0-6.0 \\
(102)\end{array}$ \\
\hline
\end{tabular}

a $\mathrm{p}<0.05$.

b $\mathrm{p}<0.01$.
Table 4 shows a synthesis of the results of the multivariate models in which the dependent variables emerged as significantly associated with parental longevity. The reference category in all the models is the NN group, i.e. subjects with non-long-lived parents.

Concerning the ability to walk $500 \mathrm{~m}$ unassisted, LL and LN groups have a higher odds ratio in comparison to NN subjects even though this difference reaches statistical significance only for LN subjects. The ability to perform the chair-stand test and hand grip strength are significantly higher in LN group than in NN group. LL group shows a similar trend to group LN, with p-values close to statistical significance ( $p=0.058$ in both cases).

Regarding pathologies and related aspects, a reduced risk is observed in LN and LL subjects compared to NN subjects.

Considering both qualitative and quantitative assessments of perceived health, the most favorable group is that with one long-lived parent. The same applies as concerns the onset of infarction or stroke (these two pathologies have been considered together in order to increase the number of affected cases in the analysis). LL group appears to be significantly favored for cancer and chronic obstructive pulmonary disease (COPD), however the odds ratio for LN group is not far from statistical significance $(\mathrm{p}=0.065$ and $\mathrm{p}=0.083$, respectively).

\section{Table 4}

Synthesis of the multivariate regression models in which the dependent variables emerged as significantly associated with parental longevity. All the models adjusted for socio-demographic characteristics, BMI, physical activity, smoking and wine consumption.

\begin{tabular}{|c|c|c|c|}
\hline Variable & Group $^{a}$ & $\begin{array}{l}\text { Effect measure estimate } \\
(95 \% \mathrm{CI})\end{array}$ & p-Value \\
\hline \multirow{2}{*}{$\begin{array}{l}\text { Ability to walk } 500 \mathrm{~m} \\
\text { without help }\end{array}$} & LN & OR: 5.113 (1.586 16.485) & 0.001 \\
\hline & LL & OR: 4.911 (0.909 26.519) & 0.064 \\
\hline \multirow{2}{*}{$\begin{array}{l}\text { Ability to perform the } \\
\text { chair-stand test }\end{array}$} & $\mathrm{LN}$ & OR: 5.031 (1.709 14.812) & 0.006 \\
\hline & LL & OR: 4.629 (0.882 24.291) & 0.070 \\
\hline \multirow[t]{2}{*}{ Hand grip strength } & $\mathrm{LN}$ & $\beta: 1.661$ (0.213 3.109) & 0.025 \\
\hline & LL & $\beta: 1.495(-0.1953 .185)$ & 0.083 \\
\hline \multirow[t]{2}{*}{ Self-rated health score } & $\mathrm{LN}$ & $\beta: 4.072(0.0878 .058)$ & 0.045 \\
\hline & LL & $\beta: 3.310(-1.3497 .968)$ & 0.163 \\
\hline \multirow{2}{*}{$\begin{array}{l}\text { Perceived health "good" } \\
\text { or "very good" }\end{array}$} & $\mathrm{LN}$ & OR: 2.080 (1.208 3.575) & 0.008 \\
\hline & LL & OR: 1.368 (0.728 2.569) & 0.330 \\
\hline \multirow[t]{2}{*}{ Stroke or myocardial infarction } & LN & OR: 0.238 (0.089 0.639) & 0.004 \\
\hline & LL & OR: 0.479 (0.169 1.356) & 0.166 \\
\hline \multirow[t]{2}{*}{ Hypertension } & $\mathrm{LN}$ & OR: $0.457(0.2600 .803)$ & 0.006 \\
\hline & LL & OR: 0.481 (0.250 0.927) & 0.029 \\
\hline \multirow[t]{2}{*}{ Cancer } & $\mathrm{LN}$ & OR: $0.500(0.2391 .044)$ & 0.065 \\
\hline & LL & OR: 0.371 (0.138 0.997) & 0.049 \\
\hline \multirow[t]{2}{*}{ COPD } & $\mathrm{LN}$ & OR: $0.366(0.1181 .138)$ & 0.083 \\
\hline & LL & OR: 0.115 (0.013 0.988) & 0.049 \\
\hline \multirow[t]{2}{*}{ Chronic therapy } & $\mathrm{LN}$ & OR: $0.304(0.1230 .752)$ & 0.010 \\
\hline & LL & OR: $0.232(0.0900 .600)$ & 0.003 \\
\hline \multirow[t]{2}{*}{ Number of drugs taken daily } & $\mathrm{LN}$ & IRR: 0.635 (0.551 0.730) & $<0.001$ \\
\hline & LL & IRR: 0.664 (0.555 0.795) & $<0.001$ \\
\hline
\end{tabular}

\footnotetext{
${ }^{a}$ NN group is the reference category.
} Significant p-values are reported in italics. 
Lastly, the advantage of the groups with one or two long-lived parents in comparison to non-long-lived parents appears very similar for hypertension, use of chronic therapy and number of drugs taken daily.

Using the estimates obtained from the multivariate models, the comparison between the LL and LN groups did not show statistically significant differences for each dependent variable.

\section{Discussion}

The aim of this study was to evaluate the advantage, in terms of health and functional status, that may derive from having one centenarian parent and one long-lived or, alternatively, one centenarian parent and one non-long-lived, in comparison with the condition of those with neither parents long-lived. To this end it was decided to apply a restrictive demographic criterion to define when considering the second parent long-lived or not. This criterion was based on death distribution estimates for the birth cohorts of reference, so as to guarantee that death occurred at a later age than the modal ages of death.

The results obtained in this work seem to indicate that the state of health of subjects without long-lived parents is on the whole worse than the health of individuals with one or two long-lived parents. This trend emerges clearly for pathologies concerning the three main groups of death causes in the elderly, i.e. cardiovascular diseases with related risk factors, cancer and respiratory diseases. Moreover, the fact that subjects with at least one long-lived parent have a significantly reduced risk of taking drugs for chronic therapy, and take a significantly reduced number of drugs when compared to the NN subjects, is worth noting because the use of drugs can effectively synthesize the overall state of health.

Our results concerning the risk of age-related diseases and the use of drugs in centenarians' offspring compared to age-matched controls are consistent with data obtained in previous studies and reinforce the notion that longevity runs in families and that centenarians' offspring are more likely to age in better health and with a lower mortality than their peers (Adams et al., 2008). Recent studies suggest that these observations can be also applied to nonagenarian families. Indeed, data from the Leiden Longevity Study on offspring of nonagenarian siblings indicate a preserved insulin sensitivity, a lower prevalence of myocardial infarction, hypertension, diabetes mellitus and use of cardiovascular medication with respect to their partners (Westendorp et al., 2009; Wijsman et al., 2011).

For the first time this study extends the comparison between centenarians' offspring and offspring of non-long-lived parents to functional status assessment, an extremely important factor in the general state of health of the elderly. Significant or almost significant differences in the ability to perform the chair-stand test and, for women, hand grip strength have been observed. A previous work, analyzing offspring of nonagenarian subjects, suggested that handgrip was not a marker of familial longevity (Ling et al., 2012). This apparent discrepancy may be due to the different ages of offspring participants in the two studies. In particular, the subjects recruited in our study, being offspring of centenarians, are ten years older on average, attaining an age critical for the onset of age-related decline. However, it can be hypothesized that at older ages the differences in functional and health status might emerge more clearly.

Moreover, the fact that differences in the hand grip strength are significant among females and not among males is in line with the general observation that, in the elderly, men enjoy better functional status than women of the same age (Crimmins et al., 2011) and does not rule out the possibility that the differences between the groups may appear in older males.

The parents' longevity seems also to impact on body mass index, even though only in females significantly. It is observed in fact that LL group has the lowest values, while NN group has the highest. This aspect is worth noting because the BMI seems to act as a confounding variable in the regression models, either concerning functional status or pathologies and the use of pharmaceutical drugs.

Although for some of the variables analyzed a significant difference was sometimes noted only for one of the two LL or LN groups in comparison with the NN group, overall the advantage in state of health of this sample of people around 70 years of age appears similar between those with one or both long-lived parents. Indeed, on the whole, the coefficient values of regression or the odds ratios are similar in the two groups, and often when p-values reach statistical significance in one of the two groups they are not far removed either. It therefore seems possible to conclude that at ages around 70 years the genetic contribution to health status deriving from having one centenarian parent is not substantially improved if the other parent is also long-lived. This finding is reinforced by the fact that, as discussed earlier, it was decided to choose a rather high threshold for longevity ( 81 years or older for males and 87 years or older for females).

Indeed, diverse studies show that the genetic influence on aging is the highest in extremely long-living individuals and that the heritability of longevity increases with the increase of the threshold used to define longevity (Cevenini et al., 2010; Gögele et al., 2011). Some genetic effect would probably be observed in the strongly unlikely event that also the second parent was extremely long-lived.

In conclusion, the results of this study confirm largely that the offspring of centenarians represent an appropriate model for research on healthy aging, suggesting that the longevity of the non-centenarian parent seems to be irrelevant for the functional and general health status of the offspring. However, our results refer to a sample of subjects with a mean age of about 70 years and do not exclude that at older ages the longevity of the second parent can became a relevant factor. Further studies are needed to answer this interesting question, in particular it is urgent to plan a longitudinal study, checking periodically the health status of the participants.

\section{Acknowledgements}

This research was funded by grants from the University of Bologna, University of Florence and MIUR (PRIN 2006) to CF and DM.

\section{References}

Adams, E.R., Nolan, V.G., Andersen, S.L., Perls, T.T., Terry, D.F., 2008. Centenarian offspring: start healthier and stay healthier. J. Am. Geriatr. Soc. 56 (11), 2089-2092.

Atzmon, G., Schechter, C., Greiner, W., Davidson, D., Rennert, G., Barzilai, N., 2004. Clinical phenotype of families with longevity. J. Am. Geriatr. Soc. 52 (2), 274-277.

Cevenini, E., Bellavista, E. Tieri, P. Castellani, G., Lescai, F., Francesconi, M., Mishto, M. Santoro, A., Valensin, S., Salvioli, S., Capri, M., Zaikin, A., Monti, D., de Magalhães, J.P., Franceschi, C., 2010. Systems biology and longevity: an emerging approach to identify innovative anti-aging targets and strategies. Curr. Pharm. Des. 16 (7), 802-813.

Crimmins, E.M., Kim, J.K., Solé-Auró, A., 2011. Gender differences in health: results from SHARE, ELSA and HRS. Eur. J. Public Health 21 (1), 81-91.

De Benedictis, G., Franceschi, C., 2006. The unusual genetics of human longevity. Sci. Aging Knowledge Environ. 28 (10), 20.

Evert, J., Lawler, E., Bogan, H., Perls, T., 2003. Morbidity profiles of centenarians: survivors, delayers, and escapers. J. Gerontol. A Biol. Sci. Med. Sci. 58 (3), 232-237.

Franceschi, C., Motta, L., Valensin, S., Rapisarda, R., Franzone, A., Berardelli, M., Motta, M., Monti, D., Bonafé, M., Ferrucci, L., Deiana, L., Pes, G.M., Barbi, C., Sartoni, G., Gemelli, C., Lescai, F., Olivieri, F., Marchegiani, F., Cardelli, M., Cavallone, L., Gueresi, P., Cossarizza, A., Troiano, L., Pini, G., Sansoni, P., Passeri, G., Lisa, R., Spazzafumo, L., Amadio, L., Giunta, S., Stecconi, R., Morresi, R., Viticchi, C., Mattace, R., De Benedictis, G., Baggio, G., the Italian Multicenter Study on Centenarians (IMUSCE), 2000. Do men and women follow different trajectories to reach extreme longevity? Aging Clin. Exp. Res. 12, 77-84.

Franceschi, C., Bezrukov, V., Blanché, H., Bolund, L., Christensen, K., de Benedictis, G., Deiana, L., Gonos, E., Hervonen, A., Yang, H., Jeune, B., Kirkwood, T.B., Kristensen, P., Leon, A., Pelicci, P.G., Peltonen, L., Poulain, M., Rea, I.M., Remacle, J., Robine, J.M., Schreiber, S., Sikora, E., Slagboom, P.E., Spazzafumo, L., Stazi, M.A., Toussaint, O., Vaupel, J.W., 2007a. Genetics of healthy aging in Europe: the EU-integrated project GEHA (Genetics of Healthy Aging). Ann. N. Y. Acad. Sci. 1100, 21-45.

Franceschi, C., Capri, M., Monti, D., Giunta, S., Olivieri, F., Sevini, F., Panourgia, M.P., Invidia, L., Celani, L., Scurti, M., Cevenini, E., Castellani, G., Salvioli, S., 2007b. Inflammaging and anti-inflammaging: a systemic perspective on aging and longevity emerged from studies in humans. Mech. Ageing Dev. 128 (1), 92-105. 
Gögele, M., Pattaro, C., Fuchsberger, C., Minelli, C., Pramstaller, P.P., Wjst, M., 2011. Heritability analysis of life span in a semiisolated population followed across four centuries reveals the presence of pleiotropy between life span and reproduction. J. Gerontol. A Biol. Sci. Med. Sci. 66 (1), 26-37.

Gueresi, P., Troiano, L., Minicuci, N., Bonafé, M., Pini, G., Salvioli, G., Carani, C., Ferrucci, L., Spazzafumo, L., Olivieri, F., Cavrini, G., Valentini, D., Franceschi, C., 2003. The MALVA (MAntova LongeVA) Study: an investigation on people 98 years of age and over in a province of Northern Italy. Exp. Gerontol. 38, 1189-1197.

Human Mortality Database, e. University of California, Berkeley (USA), and Max Planck Institute for Demographic Research (Germany). Available at www.mortality. orgwww.humanmortality.de.

Ling, C.H., de Craen, A.J., Slagboom, P.E., Westendorp, R.G., Maier, A.B., 2012. Handgrip strength at midlife and familial longevity: The Leiden Longevity Study. Age (Dordr.) 34 (5), 1261-1268.

Olivieri, F., Spazzafumo, L., Antonicelli, R., Marchegiani, F., Cardelli, M., Sirolla, C. Galeazzi, R., Giovagnetti, S., Mocchegiani, E., Franceschi, C., 2008. Combination of biomarkers to predict mortality in elderly patients with myocardial infarction. Mech. Ageing Dev. 129 (4), 231-237.

Paolisso, G., Gambardella, A., Ammendola, S., D'Amore, A., Balbi, V., Varricchio, M., D'Onofrio, F., 1996. Glucose tolerance and insulin action in healthy centenarians. Am. J. Physiol. 270, 890-894.

Passeri, G., Pini, G., Troiano, L., Vescovini, R., Sansoni, P., Passeri, M., Gueresi, P., Delsignore, R., Pedrazzoni, M., Franceschi, C., 2003. Low vitamin D status, high bone turnover, and bone fractures in centenarians. J. Clin. Endocrinol. Metab. 88 (11), 5109-5115.

Perls, T.T., Wilmoth, J., Levenson, R., Drinkwater, M., Cohen, M., Bogan, H., Joyce, E., Brewster, S., Kunkel, L., Puca, A., 2002. Life-long sustained mortality advantage of siblings of centenarians. Proc. Natl. Acad. Sci. U. S. A. 99 (12), 8442-8447.
Salvioli, S., Capri, M., Bucci, L., Lanni, C., Racchi, M., Uberti, D., Memo, M., Mari, D. Govoni, S., Franceschi, C., 2009. Why do centenarians escape or postpone cancer? The role of IGF-1, inflammation and p53. Cancer Immunol. Immunother. 58 (12) 1909-1917.

Spazzafumo, L., Olivieri, F., Abbatecola, A.M., Castellani, G., Monti, D., Lisa, R., Galeazzi, R., Sirolla, C., Testa, R., Ostan, R., Scurti, M., Caruso, C., Vasto, S., Vescovini, R., Ogliari, G., Mari, D., Lattanzio, F., Franceschi, C., 2011. Remodelling of biological parameters during human ageing: evidence for complex regulation in longevity and in type 2 diabetes. Age (Dordr.) 16

Terry, D.F., Wilcox, M., McCormick, M.A., Lawler, E., Perls, T.T., 2003. Cardiovascular advantages among the offspring of centenarians. J. Gerontol. A Biol. Sci. Med. Sci. 58 (5), 425-431. Erratum in: J. Gerontol. A Biol. Sci. Med. Sci. 63 (7), 706.

Terry, D.F., McCormick, M., Andersen, S., Pennington, J., Schoenhofen, E., Palaima, E., Bausero, M., Ogawa, K., Perls, T.T., Asea, A., 2004a. Cardiovascular disease delay in centenarian offspring: role of heat shock proteins. Ann. N. Y. Acad. Sci. 1019, 502-505.

Terry, D.F., Wilcox, M.A., McCormick, M.A., Pennington, J.Y., Schoenhofen, E.A., Andersen, S.L., Perls, T.T., 2004b. Lower all-cause, cardiovascular, and cancer mortality in centenarians offspring. J. Am. Geriatr. Soc. 52 (12), 2074-2076.

Westendorp, R.G., van Heemst, D., Rozing, M.P., Frölich, M., Mooijaart, S.P., Blauw, G.J., Beekman, M., Heijmans, B.T., de Craen, A.J., Slagboom, P.E., 2009. Leiden Longevity Study Group, 2009. Nonagenarian siblings and their offspring display lower risk of mortality and morbidity than sporadic nonagenarians: The Leiden Longevity Study. J. Am. Geriatr. Soc. 57 (9), 1634-1637.

Wijsman, C.A., Rozing, M.P., Streefland, T.C., le Cessie, S., Mooijaart, S.P., Slagboom, P.E. Westendorp, R.G., Pijl, H., van Heemst, D., Leiden Longevity Study group, 2011. Familial longevity is marked by enhanced insulin sensitivity. Aging Cell 10 (1), 114-121. 